\title{
MEMES DE INTERNET, AÇÃO DISCURSIVA E LETRAMENTO CRÍTICO NA ESFERA PÚBLICA DIGITAL
}

\author{
Isnalda Berger de Figueiredo Alves Filha ${ }^{1}$ \\ Úrsula Cunha Anecleto ${ }^{2}$ \\ Ivana Carla Oliveira Sacramento ${ }^{3}$
}

\section{Resumo}

Este artigo, de abordagem teórico-conceitual, tem como objetivo apresentar reflexões sobre a emergência de novos gêneros discursivos, a exemplo dos memes de internet, potencializados pelas esferas públicas digitais. Nessa perspectiva, atenta-se para a análise desses textos, de forma crítica e fundamentada argumentativamente, a partir do estabelecimento de ações discursivas, levando-se em conta características do gênero e a sua funcionalidade comunicativa. Espera-se com esse estudo contribuir para a reflexão de professores da Educação Básica, no sentido de compreender e, assim, ampliar

\footnotetext{
${ }^{1}$ Possui Mestrado em Estudos Linguísticos, na linha de pesquisa Práticas Textuais e Discursivas (MEL/UEFS), graduação em Letras, Língua Portuguesa e Literaturas pela Universidade do Estado da Bahia (2009), Especialização em Ensino de Língua Portuguesa (Instituto Pró-Saber) e Especialização em Linguística e Ensino - Aprendizagem de Língua Portuguesa pela Universidade Estadual de Feira de Santana. É professora de Língua Portuguesa da Educação Básica, na rede pública de ensino.

${ }^{2}$ Doutora em Educação na linha de pesquisa Estudos Culturais, pela Universidade Federal da Paraíba (UFPB). Mestra em Crítica Cultural na linha de pesquisa Letramento, Identidade e Formação do Professor, pela Universidade do Estado da Bahia (UNEB). Graduada em Letras Vernáculas pela Universidade Estadual de Feira de Santana (UEFS). Atualmente, é docente no Mestrado Profissional em Educação e Diversidade (MPED/UNEB) e no Programa de Pós-graduação em Estudos Linguísticos (PPGEL) na Universidade Estadual de Feira de Santana (UEFS), docente de Prática Pedagógica, Estágio em Língua Portuguesa, Tecnologias da Informação e Comunicação e Fundamentos Metodológicos da Língua Portuguesa (UNEB/ campus XIV / campus IV). É vice-líder do Grupo de Estudo e Pesquisa em (Multi)letramentos, Educação $\quad$ e $\quad$ Tecnologias na UNEB (dgp.cnpq.br/dgp/espelhogrupo/5640144801632064) e membro pesquisador do Grupo de Pesquisa Educação, Redes Sociotécnicas e Culturas digitais na UFBA.
}

${ }^{3}$ Doutora em Língua e Cultura (UFBA), na linha de pesquisa Aquisição, ensino e aprendizagem de línguas. Mestra em Crítica Cultural, na linha de pesquisa Letramento, identidades e formação de professores, pela Universidade do Estado da Bahia (UNEB). Especialista em Estudos Literários (UNEB), graduada em Letras Vernáculas com Inglês (UNEB). É docente da Secretaria de Educação do Estado da Bahia e desde 2003 trabalha com formação continuada de professores, atuando principalmente nos seguintes temas: letramento, ensino e aprendizagem de língua portuguesa (e seus contextos culturais), formação de professores. É docente da Faculdade de Tecnologias e Ciências da Bahia (FATEC) e da Faculdade SS. Sacramento (FSSS). 
práticas de ensino em que gêneros discursivos da esfera digital façam parte de práticas letradas, de forma crítica, nas salas de aula.

Palavras-chave: Memes de internet. Ação Discursiva. Letramento Crítico. Esfera Pública Digital. Gêneros Discursivos.

\title{
MEMES OF THE INTERNET, DISCURSIVE ACTION AND CRITICAL LITERACY IN THE DIGITAL PUBLIC SPHERE
}

\begin{abstract}
This article, with a theoretical-conceptual approach, aims to present reflections on the emergence of new discursive genres, such as internet memes, powered by digital public spheres. From this perspective, we analyze the analysis of these texts, in a critical and argumentatively based way, from the establishment of discursive actions, taking into account characteristics of the genre and the communicative functionality. It is hoped that this study will contribute to the reflection of teachers of Basic Education, in the sense of understanding and, thus, expanding teaching practices in which discursive genres of the digital sphere are part of critical literacy practices in classrooms.
\end{abstract}

Keywords: Memes of the internet. Discursive Action. Critical Literature. Digital Public Sphere. Discursive Genres.

\section{MEMES DE INTERNET, ACCIÓN DISCURSIVA Y LETRAMIENTO CRÍTICO EN LA ESFERA PÚBLICA DIGITAL}

\section{Resumen}

Este artículo, de enfoque teórico-conceptual, tiene como objetivo presentar reflexiones sobre la emergencia de nuevos géneros discursivos, a ejemplo de los memes de internet, potenciados por las esferas públicas digitales. En esta perspectiva, se atenta para el análisis de estos textos, de forma crítica y fundamentada argumentativamente, a partir del establecimiento de acciones discursivas, teniendo en cuenta características del género y de la funcionalidad comunicativa. Se espera con ese estudio contribuir a la reflexión de profesores de la Educación Básica, en el sentido de comprender y, así, ampliar prácticas de enseñanza en que géneros discursivos de la esfera digital formen parte de prácticas letradas, de forma crítica, en las aulas.

Palabras clave: Memorias de Internet. Acción Discursiva. Lector Crítico. Esfera Pública Digital. Géneros Discursivos 


\section{Considerações Iniciais}

A pluralidade marca a vida em sociedade. A multiplicidade está presente no sistema econômico, político e cultural, pairando em toda a dinâmica social. Isso não quer dizer que em tempos mais antigos não existia a diversidade. Ocorre que junto com o progresso e as transformações sociais que englobam as relações pessoais, condições de trabalho, os modos de produção, de consumo vieram outras possibilidades de desenvolvimento e ascensão do sujeito, estreitando as suas relações com o outro e com novos artefatos sociais. $\mathrm{O}$ modo de interagir, trocar informações e produzir conhecimento passou por mudanças que culminaram em formas de comunicação mais dinâmicas e coletivas.

A diversidade está presente, também, em esferas públicas comunicativas e nas manifestações linguísticas ali presentes. Em constante transformação, consideram-se as esferas como o lugar da interação, do debate, da problematização e da formação da opinião pública. Nesse cenário, predomina a diversidade de opiniões, ideias, valores e crenças do sujeito, que pode manifestar-se também através de múltiplas linguagens. Em uma sociedade cada vez mais conectada, a noção de esfera pública (HABERMAS, 1997) passou por uma ampliação. Além de assembleias, manifestações populares em grandes centros urbanos, congressos, até mesmo encontros de amigos, reuniões familiares, por exemplo, surgiram as esferas públicas digitais, como as redes sociais, que possibilitam a formação de espaços democráticos para formação da opinião pública ao fomentar a manifestação e problematização de ideias dos sujeitos.

As Tecnologias da Informação e Comunicação (TIC) conectadas à internet, a partir de suas potencialidades interativas, intensificaram o surgimento de outras esferas públicas, legitimando esses espaços enquanto redes de comunicação de conteúdo, informação, opinião etc. (HABERMAS, 1997) entre as pessoas. Nesse contexto, também, propagaram-se novos gêneros discursivos, a exemplo de memes de internet, que têm estreita relação com a rápida disseminação de informações nos espaços virtuais.

Assim, as TIC assumem um papel de destaque para o surgimento e desenvolvimento de esferas públicas. Através dessas esferas, os sujeitos podem agir comunicativamente uns com os outros, problematizando e emitindo opiniões sobre diversos temas, mediatizados por uma gama de gêneros discursivos que fazem parte do processo textual multifacetado da atualidade. 
Nesse cenário, é notória a importância de, na Educação Básica, atentar-se para o surgimento das esferas públicas e das textualidades presentes nessas novas oportunidades de interação social. Entende-se que os estudantes precisam ler, compreender e produzir textos que circulam nesses espaços, caracterizados pela multimodalidade e multissemiose, ampliando, assim, suas ações discursivas, de forma crítica.

Diante dessas considerações, este artigo apresenta uma análise teórico-conceitual sobre essas novas configurações discursivas da atualidade, encontradas nas esferas públicas digitais, com o objetivo de apresentar características dos memes de internet enquanto gênero discursivo e suas funcionalidades comunicativas. Espera-se, com este trabalho, contribuir para a reflexão de professores da Educação Básica, no sentido de compreender e, assim, ampliar práticas de ensino em que gêneros discursivos da esfera digital façam parte de práticas letradas, de forma crítica, na sala de aula.

\section{Memes de internet enquanto gêneros discursivos: aportes teóricos}

A concepção bakhtiniana de gêneros discursivos aponta que o texto é muito mais que materialidade linguística. Bakhtin (1997) buscou analisar o aspecto social da linguagem, ultrapassando os limites dos estudos formais que consideravam apenas os aspectos morfossintáticos, lexicais e fonológicos dos textos e, para isso, alguns conceitos foram reavaliados.

Assim, os textos, materializados pelos gêneros, são definidos como tipos relativamente estáveis de enunciados (BAKHTIN, 1997), caracterizados pela dinamicidade e adequação. Dessa forma, eles podem aparecer tanto na modalidade oral, como escrita, com registros formais e informais. Partindo da relação dos gêneros com a perspectiva social da linguagem, não é possível estabelecer uma quantidade de gêneros encontrados nas esferas de comunicação. Eles surgem ou se adéquam de acordo com as transformações sociais, as relações pessoais, os modos de produção textual e de conhecimento, as relações de trabalho e novas formas de comunicação mais interativas e participativas.

No entanto, evidencia-se que essa dinamicidade não representa desordem, com a noção de que se pode fazer o que quiser com os gêneros. A partir da função comunicativa, eles conservam certa essência, mantendo então um equilíbrio entre os 
elementos que os caracterizam e a integração de novas peculiaridades. Bakhtin (1997, p. 279) explica os três elementos que constituem os gêneros:

O enunciado reflete as condições específicas e as finalidades de cada uma dessas esferas, não só por seu conteúdo (temático) e por seu estilo verbal, ou seja, pela seleção operada nos recursos da língua recursos lexicais, fraseológicos e gramaticais - mas também, e sobretudo, por sua construção composicional. Estes três elementos (conteúdo temático, estilo e construção composicional) fundem-se indissoluvelmente no todo do enunciado, e todos eles são marcados pela especificidade de uma esfera de comunicação.

A construção dos sentidos dos enunciados dá-se a partir da fusão desses três elementos: conteúdo temático, estilo e construção composicional. Analisá-los separadamente seria um equívoco, pois é na vinculação desses fatores, associados a uma esfera de comunicação (literária, jornalística, jurídica etc.), que o gênero discursivo se concretiza. Dessa forma, estilo refere-se às

[...] escolhas linguísticas que fazemos para dizer o que queremos dizer ("vontade enunciativa"), para gerar o sentido desejado. Essas escolhas podem ser do léxico (vocabulário), estrutura frasal (sintaxe), do registro linguístico (formal/informal, gírias) etc. (BARBOSA; ROJO, 2015. p. 92).

Durante a produção dos enunciados, o autor faz uma seleção das formas linguísticas que considera mais adequadas ao seu texto, a partir das suas intenções comunicativas, o que ele pretende comunicar, quem são seus interlocutores, quais as informações que serão implícitas e explícitas do enunciado. O estilo está diretamente relacionado ao contexto sociointeracional, ao gênero discursivo e à esfera de comunicação verbal em que os interlocutores estão inseridos. Dessa forma,

O estilo é indissociavelmente vinculado a unidades temáticas determinadas e, o que é particularmente importante, a unidades composicionais: tipo de estruturação e de conclusão de um todo, tipo de relação entre o locutor e os outros parceiros da comunicação verbal (relação com o ouvinte, ou com o leitor, com o interlocutor, com o discurso do outro, etc. $\mathrm{O}$ estilo entra como elemento na unidade de gênero de um enunciado. Isso não equivale a dizer, claro, que o estilo linguístico não pode ser objeto de um estudo específico, especializado. Tal estudo, ou seja, uma estilística da língua, concebida como uma descrição autônoma, é possível e necessário. Porém, para ser correto e produtivo, este estudo sempre deve partir do fato de que os estilos da língua pertencem por natureza ao gênero e deve basear-se no estudo prévio dos gêneros em sua diversidade (BAKHTIN, 1997, p. 284). 
A construção composicional está associada à organização do gênero, “[...] ao que a teoria textual chama de "(macro/super) estrutura" do texto, à progressão temática, à coerência e coesão do texto" (BARBOSA; ROJO, 2015. p. 94). Já o conteúdo temático “[...] não é o assunto específico de um texto, mas o domínio de sentido de que se ocupa o gênero" (FIORIN, 2016, p. 69).

A combinação desses elementos dará forma ao gênero, colaborando para a construção dos sentidos do texto. Isso também permite que sejam identificados pelos interlocutores criando uma expectativa da temática e da função comunicativa do enunciado. A partir da perspectiva bakhtiniana de gênero discursivo, levanta-se uma discussão sobre a configuração de novos gêneros que têm disseminados no ciberespaço como, por exemplo, os memes de internet.

Dessa forma, os memes de internet configuram-se como gêneros discursivos híbridos que são compartilhados em aplicativos de mensagens e redes sociais, caracterizados pela leitura rápida, criatividade e dinamismo do espaço virtual. Enquanto enunciados, possuem materialidade linguística bastante peculiar, sendo produzidos por sujeitos imersos em diferentes contextos sociais, culturais e históricos.

\section{Gênero discursivo memes de internet}

Os gêneros discursivos vistos no espaço virtual são marcados pela capacidade criativa dos sujeitos que navegam pelo ciberespaço. Atualmente, os memes de internet ganharam destaque nas redes sociais e aplicativos de mensagens, despertando não só a curiosidade, mas discussões importantes sobre como esses gêneros espalham-se, chegando tão rapidamente aos meios digitais. Sujeitos interconectados são capazes de transformar notícias diárias, fatos cotidianos, cenas de filmes, novelas, séries ou conversas informais em memes que aguçam a imaginação dos usuários da rede, seja provocando o riso ou problematizando questões sociais, políticas, econômicas etc.

O conceito de meme não é novo. Na década de 70, Richard Dawkins criou o termo baseando-se na teoria da evolução das espécies e comparou a evolução cultural com a evolução genética. O meme seria o gene da cultura que é perpetuada pelas pessoas (RECUERO, 2009). Trata-se de vídeos, imagens estáticas ou em movimento, piadas, jogos, frases que são compartilhados nas esferas públicas digitais de forma bastante rápida. A multimodalidade e multissemiose são características inerentes. É muito comum combinar imagens (pessoas famosas, animais, cenas de filme, objetos) 
com frases curtas, utilizando sites especializados em gerar memes ou aplicativos de celular.

Recuero (2009) relaciona a difusão de informações nas redes sociais à criação e à propagação de memes. Entende-se que as publicações feitas nas esferas públicas digitais não acontecem de forma casual, mas são motivadas pela percepção de valor que as informações divulgadas possuem. Como enunciado dotado de sentidos, a criação e o compartilhamento dos memes ocorrem de forma diversificada, de acordo com os valores que apresentam e como podem influenciar as interações sociais na rede.

Nesse sentido, associa-se a criação de memes com o capital social. O capital social seria “[...] um valor constituído a partir das interações entre os atores sociais" (RECUERO, 2009, p. 45). “[...] Refere-se à conexão entre indivíduos - redes sociais e normas de reciprocidade e confiança que emergem dela" (PUTNAM apud RECUERO, 2009, p. 45).

\begin{abstract}
A presença de memes é relacionada ao capital social, na medida em que a motivação dos usuários para espalhá-las é, direta ou indiretamente, associada a um valor de grupo. Por exemplo, as pessoas que espalham os recados com imagens acreditam estar fazendo algo positivo, que deixará aquele que recebeu a mensagem contente. Logo, há intencionalidade na construção/aprofundamento de um laço social, que é ultimamente explicado pela necessidade de capital social (RECUERO, 2009, p. 130).
\end{abstract}

Dessa forma, ao criar um meme, o sujeito pretende interagir e entender-se com o outro, sendo que o enunciado criado por ele atende a interesses de grupos que curtem, compartilham e comentam determinados memes. Existem páginas na internet que publicam memes relacionados à cultura nordestina, por exemplo; atraem um público que se identifica e compartilha os memes criados com a intenção de fortalecer e divulgar costumes do povo nordestino, desde a culinária, músicas, dança e identidade linguística.

Em seguida, a autora cita alguns valores e motivações com o objetivo de entender a sua relação com os capitais sociais representados nos memes. O valor da autoridade indica aqueles sujeitos que possuem uma influência significativa nas redes sociais. Os blogueiros são exemplos bem atuais de influenciadores nas redes, podendo inspirar práticas esportivas, tendências de moda e beleza, debates políticos etc. "[...] Se este blogueiro colocar um link no twitter e disser "vejam que legal", é bastante provável que vários atores cliquem no link devido à influência do blogueiro" (RECUERO, 2009, p. 131). 
Também são valores a reputação de um ator social, sua popularidade e visibilidade. Os memes têm maior repercussão quando publicados em páginas com grande número de visitação, publicadas por pessoas públicas ou com grande notoriedade no espaço virtual (RECUERO, 2009). Esses valores contribuem para a criação e propagação dos memes, fazendo com que viralizem na rede, a partir de cópias ou réplicas que podem permanecer por muito tempo nos espaços virtuais. Obviamente, o compartilhamento dependerá das intenções comunicativas dos sujeitos e do fluxo de informações no ciberespaço.

Essas propriedades mostram que os memes de internet não podem ser considerados apenas como materialidade linguística. Os sentidos implícitos e explícitos desse gênero são constituídos graças a um conjunto de fatores. É preciso entendê-los enquanto enunciados portadores de valores e discursos sociais. O criador dos memes manifesta no texto seus posicionamentos discursivos, relacionados a aspectos sociais, culturais e históricos que são materializados através de linguagem multimodal e multissemiótica.

Os memes possuem algumas características comuns e, a partir delas, Recuero (2009, p. 124) propõe uma classificação interessante:

\begin{abstract}
A longevidade é a capacidade do meme de permanecer no tempo. A fecundidade é sua capacidade de gerar cópias. Por fim, a fidelidade é a capacidade de gerar cópias com maior semelhança ao meme original. Ressalte-se que a propagação dos memes é cíclica e nem sempre implica a reprodução fiel da ideia original. Ao contrário, as mudanças e transformações são frequentes e comparadas, em sua abordagem, às mutações genéticas: essenciais para a sobrevivência do meme. Assim, as diferenças através das quais as pessoas repetem as ideias são, por definição, parte do meme.
\end{abstract}

Um determinado meme, ao ser publicado na internet, pode permanecer por um longo período nas páginas virtuais. E costuma ser inspiração para a criação de vários outros memes que podem ou não conservar a ideia original. Por exemplo: em 2016, uma revista de grande circulação nacional publicou uma matéria sobre a esposa do então vice-presidente do Brasil com o seguinte título na capa: "Bela, recatada e do lar". A matéria gerou uma série de críticas e debates sobre a imagem da primeira-dama e, principalmente, sobre o papel da mulher na sociedade. Esse fato motivou a produção de vários memes nas redes sociais. Os usuários criaram textos, inclusive com as próprias fotos, ironizando a matéria publicada na revista. Além de apresentar ilustrações diversas, o enunciado passou por mudanças, como "bela, recatada e do bar" e outros 
exemplos. Mesmo com todas essas variações, os memes não abandonaram a frase original da matéria, fazendo, assim, referência ao enunciado original.

Figura 1: Meme publicado nas redes sociais

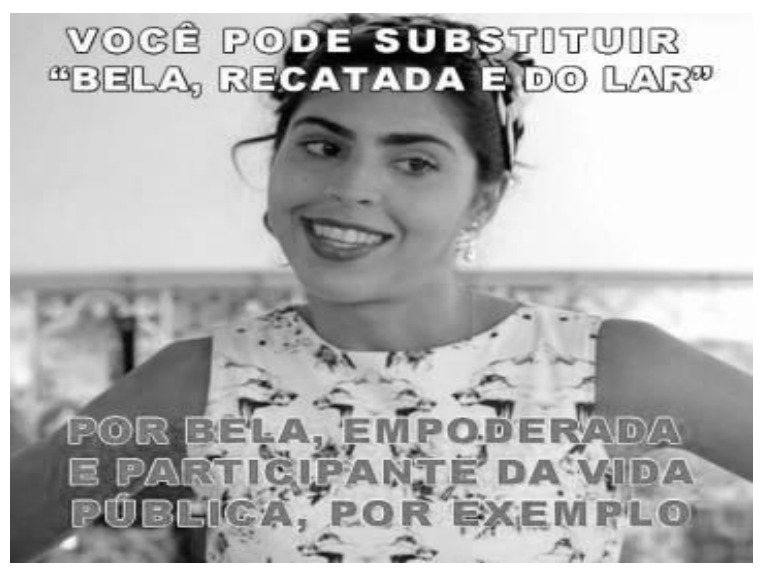

Fonte: El País. Disponível em:

https://brasil.elpais.com/brasil/2016/04/20/politica/1461175399_885009.html. Acessado em: 01 marc. 2018.

Figura 2: Meme publicado nas redes sociais

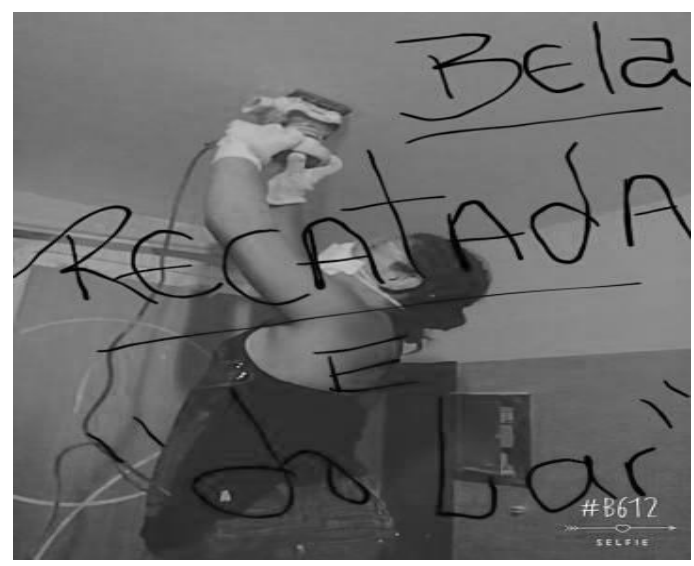

Fonte: El País. Disponível em:

https://brasil.elpais.com/brasil/2016/04/20/politica/1461175399 885009.html. Acessado em: 01 marc. 2018.

No meme da figura 1, associa-se a palavra "bela" com a apresentadora de televisão Bela Gil. O criador do meme selecionou uma cena em que a expressão facial da personagem dialoga com o texto verbal. Destaca-se e coloca entre aspas a famosa frase "bela, recatada e do lar" e propõe uma nova versão do enunciado, distinguindo-o 
com a cor vermelha, numa tentativa de chamar a atenção do leitor. Nesse caso, a definição das cores é importante para não camuflar as frases curtas que caracterizam esse tipo de meme.

$\mathrm{Na}$ figura 2, diferentemente do anterior, o meme foi construído a partir de uma cena do cotidiano sem recorrer a figuras de pessoas famosas. Trata-se de uma mulher assumindo uma função muito comum entre pessoas do sexo masculino, contrariando a ideia de que serviços como operar máquinas e equipamentos não podem ser exercidos por mulheres. A imagem não está muito colorida e percebe-se que o texto verbal não foi digitado. Aparentemente foi manuscrito com a ajuda de algum recurso. Essas características mostram pouco cuidado estético, o que também é muito comum entre os memes que são publicados e compartilhados nas redes sociais e aplicativos.

Nesses exemplos, é possível perceber as principais características dos memes não apenas quanto a aspectos estruturais, mas, também, às potencialidades interacionais, que surgem a partir da comunicação social. Mostram mulheres em situações reais do cotidiano, promovendo assim uma crítica ao papel da mulher na sociedade. São memes criados a partir de outros memes e que são bastante difundidos, embora mantenham características dos textos iniciais e que podem ser encontrados e difundidos pelo espaço virtual graças aos recursos digitais.

Enquanto enunciado dialógico, observam-se os discursos que atravessam os memes citados. Um enunciado que remete a vários outros enunciados e discursos disseminados socialmente. Nos memes das figuras 1 e 2, nota-se o confronto entre duas concepções sobre a figura feminina no meio social. Há um embate entre o enunciado original, que caracteriza a primeira dama como uma mulher exemplar, recatada, que não se envolve em escândalos, aparenta ser boa esposa, sendo confrontada pelo papel da mulher que participa da vida pública, em condições de empoderamento, que pode exercer qualquer função no mercado de trabalho e frequentar lugares antes considerados inadequados para uma mulher, a exemplo de um bar.

Nota-se a presença dos dois enunciados numa condição de enfrentamento. Os criadores dos memes partiram da ideia inicial para apresentar seu ponto de vista sobre a concepção difundida na reportagem. O leitor poderá questionar a partir daí o que representa uma mulher exemplar para a sociedade tradicional e novas concepções da figura feminina e os lugares que podem ocupar no cenário social.

A polifonia aparece nesse embate. Percebe-se a presença da voz de quem escreveu a reportagem com seu discurso conservador, a voz de quem critica e traz uma 
nova versão do enunciado "bela, recatada...". Podemos inferir que o enunciador que criou o meme contrapõe as concepções conservadoras sobre os papéis que a mulher pode assumir no cenário social, evidenciando a possibilidade de maior participação na política e no mercado de trabalho, por exemplo.

Quanto à fidelidade, alguns memes podem ser replicadores, quando apresentam pouca variação e são mais fiéis à cópia original. Outros são metafóricos, pois passam por mais mudanças quando são compartilhados e não mantém muitas características do enunciado original. Já os miméticos costumam manter a mesma estrutura da versão original, mas ocorrem algumas mudanças para adaptarem-se aos novos espaços em que são publicados (RECUERO, 2009). A mesma expressão de uma pessoa pública, a exemplo de uma atriz de novela ou de um personagem caricaturado, pode ser usada para compor diversos memes.

Referindo-se à longevidade, os memes são persistentes quando são replicados por um longo período; porém, podem desaparecer por um tempo e reaparecer na internet. "Memes persistentes parecem associar-se com memes replicadores e miméticos, pois há pouca ou nenhuma variação. Por conta disso, podem ser identificados em um largo espaço de tempo" (RECUERO, 2009, p. 127). Os voláteis não duram muito tempo e facilmente podem desaparecer ou ser transformados em outro meme.

"A persistência do meme indica pouco a respeito do tipo de valor que ele constrói, mas indica apenas que existe a valorização. Quanto mais tempo um meme permanece, mais valor está agregado à sua difusão" (RECUERO, 2009, p. 127). Nesse sentido, pode existir maior interesse pelo seu compartilhamento quando o gênero tratar de temas que atraem os sujeitos interconectados, oportunizando debates e uma forma de exposição de ideias.

O critério fecundidade dá origem a três tipos de memes: epidêmicos, globais e locais. Os memes epidêmicos se propagam com maior intensidade. Para Recuero (2009, p. 128), "todos os memes são potencialmente fecundos e necessitam gerar descendência para sobreviver, mas têm graus diferentes de fecundidade." Assim, não se pode estabelecer uma padronização relacionada ao surgimento de memes e determinar exatamente o seu alcance, se serão muito compartilhados nas redes sociais, se darão origem a muitos memes ou esquecidos facilmente pelos usuários da rede.

Os globais “[...] são memes que alcançam nós que estão distantes entre si dentro de uma determinada rede social, não sendo necessariamente fecundos. Eles 
simplesmente aparecem em pontos não próximos" (RECUERO, 2009, 128). Esses são memes difundidos com maior proximidade entre as pessoas sem muita repercussão nas mídias.

Como gênero discursivo, os memes de internet passam por processos como motivação, criação e compartilhamento. É importante atentar para sua funcionalidade comunicativa, pois é uma oportunidade de agir na esfera social. Ao criar, comentar ou publicar esses textos na rede, os indivíduos têm oportunidade de agir discursivamente, expondo suas concepções, participando de debates e formação de opinião pública através de múltiplas linguagens. Frases de estrutura linguística simples ou imagens aparentemente despretensiosas podem, em um contexto sócio-histórico, tomar grandes proporções e estreitar diálogos através das redes.

Os memes mais comuns são formados por imagem estática acrescida de uma frase curta. Os recursos linguísticos podem ser variados: usa-se uma linguagem popular, muitas vezes sem se preocupar com aspectos ortográficos, de pontuação e concordância. Normalmente, o texto verbal é disposto sem tirar o protagonismo do texto não verbal.

Para tratar sobre diversos assuntos e atingir determinado sentido, quem cria o meme pode apelar para diversos recursos linguísticos, como metáforas, ironia, abreviações, gírias, sinais de pontuação que dão ênfase ao enunciado, a exemplo da exclamação, aspas e fonte caixa alta. Também podem ser usados símbolos, signos e outros elementos que caracterizam o meme como um gênero discursivo multimodal e multissemiótico. A organização desses elementos, tanto verbais como não verbais, vai colaborar para a formação de um enunciado coerente. Os leitores que compartilham e comentam os memes poderão associar elementos externos à linguagem, percebendo a funcionalidade comunicativa dos textos que são criados a partir de um contexto culturalmente marcado.

Os memes são gêneros que representam costumes, valores, hábitos, pretensões da sociedade. Através de uma leitura rápida, é possível identificar elementos comuns aos leitores. Com seu poder de criação e difusão, os memes podem impulsionar debates significativos sobre assuntos que geram interesse de forma geral, indicando, assim, formas de agir socialmente. Entende-se que

[...] a Internet possibilita a cooperação mútua, a construção coletiva de conhecimento, fomentando os debates e ampliando, assim, o campo de evolução dos "memes". Os textos mêmicos carregam em si mensagens que são decodificadas pelos cérebros receptores, analisadas, 
interpretadas, adotadas e, por vezes, replicadas, tal que, ao se familiarizarem com a linguagem contida no componente a ser replicado, estarão dialogando de certa maneira com o criador do "meme", ou mesmo com os partícipes das mesmas interações de transmissão de ideias. É a linguagem enquanto fenômeno social, como prática de atuação interativa (SOUZA, 2013, p. 134).

Entretanto, os memes não se limitam a simples recepção, interpretação e compartilhamento de mensagens rápidas e engraçadas. Por ser um gênero discursivo sócio-historicamente situado, imerso em um contexto cultural específico, oferecem ao sujeito possibilidades de ação no espaço virtual. Ao criar e também ao comentar memes, o sujeito pode emitir opiniões, nas esferas púbicas digitais, sobre vários assuntos, participando de debates, questionando e atribuindo novos sentidos aos textos e às situações que eles podem apresentar, de forma crítica e reflexiva.

\section{Memes de internet, letramento crítico e esferas públicas digitais}

Novas textualidades, a exemplo dos memes de internet, podem fazer parte das aulas de Língua Portuguesa na Educação Básica, tendo em vista a atuação do professor no sentido de contribuir com a leitura crítica e reflexiva desse gênero discursivo. A ideia de aliar os conhecimentos didático-pedagógicos construídos à análise do discurso digital se constitui em uma proposta instigante e desafiadora ao docente. Entretanto, esta integração de conhecimentos, embora desejável, necessita estar acompanhada de fundamentos que possam, de fato, nortear as ações dos professores para que sejam bemsucedidas.

Neste sentido, um movimento teórico que pode auxiliar a concepção da criticidade dos professores e dos estudantes se encontra nos fundamentos do Letramento Crítico. A composição do Letramento Crítico contempla uma forma de pensar a prática educacional oriunda de vários campos do conhecimento como a educação, a linguística, a sociologia, os estudos políticos, culturais e filosóficos (BRASIL, 2006; JORDÃO, 2007).

Os conceitos apresentados pelo Letramento Crítico sugerem entendimentos importantes para o ensino de Língua Portuguesa, respaldados na noção de língua, discurso e poder, em especial, destacando o entendimento do que vem ser "o sujeito crítico". Jordão (2007, p. 5) explica-nos que esse tipo de letramento tem como premissa 
a formação de sujeitos críticos, "que são capazes de examinar os pressupostos e as implicações das diferentes formas de pensar e agir".

O Letramento Crítico pode ser entendido como um projeto de leitura de mundo conectado aos novos formatos culturais de usar a linguagem na contemporaneidade. No processo do ato crítico de ler, a leitura visa reconhecer a linguagem como uma prática sociocultural. A educação, por sua vez, neste entender, tem a tarefa de atuar para o desenvolvimento da consciência crítica dos sujeitos na interpretação de mundo.

Considerando que, na atualidade, os discursos digitais estão sendo produzidos e utilizados em larga escala pelas comunidades, sua introdução na vida escolar necessita de muitos investimentos. Em relação à formação dos professores, para uma atuação efetiva na relação com o discurso digital de seus alunos, faz-se necessária a busca orientada desta competência. Sendo assim, nota-se a importância de se considerar o Letramento Crítico no âmbito das reflexões contemporâneas sobre os letramentos, visto que é um referencial que defende um projeto de educação que objetiva aprender/ensinar a linguagem através do seu aprendizado reflexivo.

Essa compreensão passa pelo ensino-aprendizagem dos mais variados gêneros discursivos presentes na vida social. Para isso, as aulas de Língua Portuguesa precisam se constituir em espaços de presença, leitura e estudo dos mais variados textos, desde os cânones aos mais recentes, da literatura popular, das fotografias, das letras de canções aos posts, tweets, memes de internet etc.

Concebemos o letramento crítico como a capacidade de ler textos de modo ativo, reflexivo, a fim de compreender melhor relações de poder, de desvelar desigualdades e atos ou discursos de injustiça. O desenvolvimento das capacidades de letramento crítico promove a compreensão dos diferentes textos presentes no mundo contemporâneo, dentre eles os memes de internet. Portanto, ler textos sob essa ótica implica a reflexão crítica que permite uma tomada de posição sobre os discursos que circulam também nas esferas digitais.

Ler e produzir memes de internet são ações que envolvem a compreensão da relação existente entre as múltiplas linguagens (imagens, frases curtas etc.) e os diferentes discursos que contribuem para a construção dos sentidos dos textos. O trabalho com essas linguagens nas aulas de Língua Portuguesa promoverá debates sobre diversas temáticas, a exemplo das abordadas nos memes apresentados neste artigo, tais como preconceito, intolerância, papéis sociais estabelecidos pela sociedade e outras 
temáticas que estimulem o posicionamento crítico dos estudantes enquanto sujeitos sociais.

Além disso, ao oportunizar a criação de memes pelos estudantes, o professor estimula que o aluno selecione conteúdos, informações e recursos linguísticos para produzir seus próprios enunciados de acordo com suas intenções comunicativas.

Para isso, é importante levar em consideração o conhecimento de mundo dos estudantes, suas experiências e concepções, estimulando a reflexão sobre o contexto social, histórico e cultural representados nos memes de internet e em suas próprias realidades. É relevante incentivar, por parte dos estudantes, o confronto de ideias, refletindo sobre os discursos expressos nesses enunciados.

\section{Considerações finais}

O estudo sobre memes de internet é uma tarefa bastante desafiadora por diversos motivos: os memes são textos que acompanham a dinâmica das Tecnologias da Informação e Comunicação; apresentam uma grande variedade de estilos, organização estrutural e uma versatilidade inerentes às textualidades da esfera digital; pressupõem uma leitura crítica e contextualmente embasada. Podem ser criados a todo momento, as versões ganham ou perdem evidência muito rapidamente e também podem apresentar nova configuração de forma repentina.

O desafio é ainda maior quando pensamos em levar esses textos para as aulas de Língua Portuguesa na Educação Básica, com o objetivo de estimular o desenvolvimento de novas habilidades de leitura e de escrita, de novos letramentos, de forma crítica, em espaços democráticos de interação verbal. As esferas públicas digitais proporcionam um processo comunicativo mais ágil e multifacetado que contam com a participação de sujeitos críticos e reflexivos capazes de transformar informações em conhecimento. Assim, ressaltamos a importância de tratar das esferas digitais na escola, compreendendo as novas textualidades provenientes desses novos espaços.

Os memes de internet, enquanto gênero híbrido, proporcionam nova possibilidade de trabalho com a multimodalidade e a diversidade de linguagem, estimulando a criatividade dos estudantes, além de desenvolver práticas leitoras em meios digitais. Por tudo isso, reforçamos que os memes enquanto gêneros discursivos contribuem para a disseminação de elementos culturais, de forma crítica e reflexiva. 
Dessa forma, podem ser levados para as aulas de Língua Portuguesa pensando em outras formas de ler e de produzir textos.

\section{Referências bibliográficas}

BAKHTIN, Mikhail. Os Gêneros do Discurso. In: Estética da Criação

Verbal. 2 ed. São Paulo: Martins Fontes, 1997, p. 277-326.

BRASIL, Secretaria da educação básica. Linguagens, códigos e suas tecnologias. Brasília, 2006. 239 p. (Orientações curriculares para o ensino médio, 1).

FIORIN, José Luiz. Introdução ao pensamento de Bakhtin. 2 ed. São Paulo: Contexto, 2016. p. 21-83.

HABERMAS, Jürgen. O papel da sociedade civil e da esfera pública política. Direito e democracia: entre facticidade e validade. Vol. II. Rio de Janeiro: Tempo Brasileiro, 1997, p. 57-113.

JORDÃO, Clarissa Menezes de. As Lentes do Discurso. Letramento e criticidade no mundo digital, Campinas, v. 46, n. 1, p. 19-29, jan.-jun. 2007.

LEVY, Pierre. O ciberespaço ou a virtualização da comunicação. In:

Cibercultura. São Paulo: Editora 34, 2000, p. 85-107.

RECUERO, Raquel. Redes sociais na internet. Porto Alegre: Sulina, 2009.

ROJO, Roxane; BARBOSA, Jacqueline P. Hipermodernidade, multiletramentos e gêneros discursivos. São Paulo: Parábola Editorial, 2015.

SOUZA, Carlos Fabiano de. Memes: formações discursivas que ecoam no ciberespaço. VÉRTICES, Campos dos Goytacazes/ RJ, v.15, n. 1, p. 127-148, jan./abr. 2013.

VIEIRA, Mauricéia Silva de Paula. A leitura de textos multissemióticos: novos desafios para velhos problemas. Anais do SIELP. Volume 2, Número 1. Uberlândia: EDUFU, 2012. 